\title{
The spectrum of acute bacterial meningitis in elderly patients
}

Pere Domingo ${ }^{1 * \dagger}$, Virginia Pomar ${ }^{1 \dagger}$, Natividad de Benito ${ }^{1}$ and Pere Coll ${ }^{2}$

\begin{abstract}
Background: We conducted a prospective, observational study in Barcelona to determine the epidemiology, clinical features, and outcome of elderly patients with acute bacterial meningitis (ABM) compared with younger adults.

Methods: During 1982-2010, all patients with ABM were prospectively evaluated. There were two groups: I (15-64 years) and II ( $\geq 65$ years). All patients underwent clinical examination on admission and at discharge following a predefined protocol.

Results: We evaluated 635 episodes of ABM. The incidence was 4.03/100,000 (Group I) and 7.40/100,000 inhabitants/ year (Group II) (RR $=1.84 ; 95 \% \mathrm{Cl}: 1.56-2.17, \mathrm{P}<0.0001)$. Elderly patients had co-morbid conditions more frequently $(P<0.0001)$ and more frequently lacked fever $(P=0.0625)$, neck stiffness $(P<0.0001)$ and skin rash $(P<0.0001)$, but had an altered level of consciousness more often $(P<0.0001)$. The interval admission-start of antibiotic therapy was longer for elderly patients $(P<0.0001)$. Meningococcal meningitis was less frequent in elderly patients $(P<0.0001)$, whereas listerial $(P=0.0196)$, gram-negative bacillary $(P=0.0065)$, and meningitis of unknown origin $(P=0.0076)$ were more frequent. Elderly patients had a higher number of neurologic $(P=0.0009)$ and extra-neurologic complications $(P<0.0001)$. The overall mortality ratio was higher in elderly patients $(P<0.0001)$.
\end{abstract}

Conclusions: Elderly people are at higher risk of having ABM than younger adults. ABM in the elderly presents with co-morbid conditions, is clinically subtler, has a longer interval admission-antibiotic therapy, and has non-meningococcal etiology. It is associated with an earlier and higher mortality rate than in younger patients.

Keywords: Bacterial meningitis, Acute, Elderly, Streptococcus pneumoniae, Listeria monocytogenes, Co-morbidities, Outcome, Complications, Post-meningitic sequelae

\section{Background}

During the past years we have witnessed significant changes in the epidemiology of ABM. The most important change is the dramatic decline of incidence of meningitis due to Haemophilus influenzae serotype b (Hib) due to infant vaccination [1,2], and the striking decrease of early-onset disease caused by group B Streptococcus because of use of intra-partum antibiotic prophylaxis [3].

The incidence and pattern of many infectious diseases vary over time. These changes are due to many factors, but among them modifications in the population

\footnotetext{
* Correspondence: pdomingo@santpau.cat

${ }^{\dagger}$ Equal contributors

'Infectious Diseases Unit, Hospital de la Santa Creu i Sant Pau, Universitat Autònoma de Barcelona, Av. Sant Antoni Ma Claret, 167, Barcelona 08025, Spain

Full list of author information is available at the end of the article
}

structure stand out. Population structure in developed countries is continuously changing, and this change is mainly driven by two factors; first, the continuing aging of native population, and second the incoming migratory fluxes from developing countries. However, most likely the first one is still predominant and, therefore, elderly people are one of the fastest-growing segments in most western societies. The incidence of meningeal pathogen infections is highly influenced by the age of the patient, and $A B M$ is considered a disease of extreme ages of life [4].

The aim of our study was to determine the spectrum of ABM in elderly patients over the last 30 years, compared to a younger population from the same geographical area, both recruited from a community university hospital in Barcelona (Spain).

\section{Biomed Central}




\section{Methods}

\section{Study population}

We used data from a large, prospective, single-hospital cohort of patients with ABM enrolled over a 30-year period at the Hospital de la Santa Creu i Sant Pau (Barcelona, Spain). Our institution is a 620-bed tertiary university hospital providing care for an urban area with a population of 441,392 inhabitants. From 1982 to 2010 all consecutive adults with ABM diagnosed at our Hospital were prospectively identified and followed. The study was approved by the Ethics Committee of the Hospital de la Santa Creu I Sant Pau.

\section{Diagnosis of acute bacterial meningitis}

The diagnosis of ABM caused by a specific bacterial pathogen was based on the presence of consistent clinical findings (sudden onset of headache, fever, nausea, vomiting, neck stiffness and/or altered mental status) and one of the following: a positive cerebrospinal fluid (CSF) culture; or a negative CSF culture with a finding of pleocytosis and at least one of the following: a positive CSF antigen test, a positive blood culture, or identification of gram-negative diplococci on Gram stain of CSF in patients with a petechial or purpuric rash and a fulminant course. These last cases were considered to be caused by Neisseria meningitidis [5]. Episodes of ABM without etiologic diagnosis were included if patients had a consistent clinical picture and CSF cyto-biochemical findings consistent with purulent meningitis (pleocytosis of more than 5 polymorphonuclear leukocytes $/ \mathrm{mm}^{3}$, hypoglycorrachia defined as a CSF/blood glucose ratio $<0.50$ and high CSF protein defined as more than $45 \mathrm{mg} / \mathrm{dl}$ ) despite negative blood and negative CSF Gram stain and cultures [6,7]. Patients with viral, fungal, or mycobacterial meningitis or a history of neurosurgical procedures or traumatic head/spinal injury were excluded.

From each episode, the following data were collected: sex, age, underlying conditions, co-morbidity and co-morbidity scoring according to the Charlson index, clinical characteristics, laboratory and microbiologic results (isolates and susceptibility tests), complications, treatment, and outcome. Data were collected during the index hospitalization, and each patient was seen on admission and followed after discharge by one of the authors (PD or VP).

\section{Microbiologic methods}

Isolates were obtained from routine cultures and were identified using standard methods [8]. The disc diffusion susceptibility test was performed according to Clinical Laboratory Standards Institute (CLSI) guidelines [9], using commercially available discs (Bio-Rad ${ }^{\mathrm{TM}}$, Marnes La Coquette, France). MICs were determined using the broth micro dilution method according to the CLSI guidelines [10] using commercial panels (Sensitre, ${ }^{\mathrm{TM}}$ Trek diagnostic systems,
West Sussex, England) or Etest ${ }^{\mathrm{TM}}$ (AB Biodisk, Solna, Sweden) according to the recommendations of the manufacturer. Resistance breakpoints for penicillin were MIC $\geq$ $0.12 \mathrm{mg} / \mathrm{L}$ for pneumococcus and meningococcus [11].

\section{Definitions}

A subject aged $>14$ years was considered an adult and when aged $\geq 65$ years, elderly. Pre-admission receipt of adequate antibiotic therapy has been previously defined [12]. The interval from onset of symptoms and signs of ABM until admission was the interval symptomsadmission (ISA), whereas that from admission to the first dose of antibiotic for ABM treatment was the interval admission-therapy (IAT). Co-morbid conditions were considered to be present if the patient had a confirmed diagnosis of one or more of the following: cancer, systemic vasculitides, cirrhosis of the liver, diabetes, chronic renal failure, human immunodeficiency virus infection, heart failure, and chronic pulmonary disease [12]. Alcohol abuse was defined when alcohol intake was $>40 \mathrm{~g}$ daily [13]. Co-morbidity was graded according to the Charlson Co-morbidity Scale [14].

Extra-meningeal infection was considered when a patient had a focal infection distant from the Central Nervous System and the same pathogenic bacterium was isolated from the primary focus or from blood culture [15]. Appropriate antibiotic therapy was defined as administration of one or more antimicrobial agents shown to be effective against the meningeal pathogen, which achieve adequate CSF concentrations, commenced on admission or before neurological or systemic deterioration in inpatients [16]. Impaired mental status, seizures and focal neurologic signs after the first dose of antibiotics were considered neurological complications. The development of septic shock, acute respiratory failure, renal failure, and/or consumption coagulopathy was considered as extra-neurological complications if related to $\mathrm{ABM}$ and apparent on admission or shortly afterwards [17-22].

Nosocomial meningitis was defined as that developing more than 48 hours after admission or within one week after discharge from the hospital [23]. Coma has been defined elsewhere [17]. Inpatient deaths were considered due to $A B M$ when meningitis was the underlying and immediate cause of death. Causes of death were classified in two categories: neurological causes or systemic causes $[18,23]$. ABM was not considered to be the underlying cause of death if a disease process unrelated to meningitis began $>24 \mathrm{~h}$ after meningitis resolution and if it initiated the train of morbid events leading to death [23]. Sequelae were defined as previously outlined [12].

\section{Statistical analysis}

Continuous variables were compared using Student's $t$-test or the Mann-Whitney $U$ test when appropriate. To 
compare the incidence rates and to estimate the rate ratio plus the $95 \% \mathrm{CI}$, we used a Poisson model. We analyzed categorical data using the $\chi^{2}$ test or Fisher's exact test when indicated. Survival curves in younger patients and in those older than 65 years were compared by means of the logrank test. Statistical analyses were performed using Statistical Product and Service Solutions (SPSS) software version 16 (SPSS Inc., Chicago, IL).

\section{Results}

\section{Population studied}

From 1982 to 2010, 635 episodes of ABM were diagnosed in 623 adult patients, 427 in patients aged $15-64$ years (Group I) and 208 in patients aged $\geq 65$ years (Group II). The corresponding incidence was 4.03/ 100,000 and 7.40/100,000 inhabitants/year for group I and II, respectively ( $\mathrm{RR}=1.84 ; 95 \% \mathrm{CI}: 1.56-2.17, \mathrm{P}<$ $0.0001)$. The median yearly number of cases was 21 (95\% CI: 19-25). Demographics of the population studied are summarized in Table 1. Elderly population had co-morbid conditions more frequently (Table 1). Comorbidity predisposing to $\mathrm{ABM}$ was outstandingly frequent in meningitis by Listeria monocytogenes (87.4\%) compared with other etiologies (43.4\%) $(\mathrm{RR}=1.55,95 \%$ CI: $1.24-1.93, \mathrm{P}=0.0006)$. There were no statistically significant differences between patients from both groups in terms of gender, recurrence, and place of acquisition of $\mathrm{ABM}$ (Table 1).

\section{Clinical features}

The clinical features of patients with $A B M$ are summarized in Table 2. Patients from group II had a

Table 1 Demographics of patients with acute bacterial meningitis according to age group*

\begin{tabular}{|c|c|c|c|c|}
\hline & Group I (non-elderly) & Group II (elderly) & RR $(95 \%$ Cl) & $P$ value \\
\hline & $\mathrm{N}=427$ & $N=208$ & & \\
\hline Age (yrs) & $32.0(22.0-54.0)$ & $74.0(68.0-78.0)$ & - - & $<0.0001$ \\
\hline $15-24$ yrs (\%) & $134(31.4)$ & - - & - - & - \\
\hline $25-34$ yrs (\%) & $59(13.8)$ & - & - - & - \\
\hline 35-44 yrs. (\%) & $60(14.0)$ & - & - - & - \\
\hline $45-54$ yrs (\%) & 77 (18.0) & - & - & - \\
\hline $55-64$ yrs (\%) & $97(22.7)$ & - & - & - \\
\hline$\geq 65$ yrs (\%) & - - & $208(100)$ & - & - \\
\hline Male (\%) & $205(48.0)$ & 99 (47.6) & $0.99(0.79-1.24)$ & 0.9895 \\
\hline Co-morbidity (\%) & $168(39.3)$ & $148(71.1)$ & $2.49(1.93-3.22)$ & $<0.0001$ \\
\hline Cancer $^{\dagger}(\%)$ & $46(10.8)$ & $40(19.2)$ & $1.52(1.17-1.97)$ & 0.0051 \\
\hline Alcohol abuse (\%) & $43(10.1)$ & $21(7.1)$ & $1.00(0.69-1.45)$ & 0.8963 \\
\hline Liver cirrhosis (\%) & $15(3.5)$ & $8(3.8)$ & $1.06(0.60-1.88)$ & 0.9878 \\
\hline Diabetes mellitus (\%) & $35(8.2)$ & $46(22.1)$ & $1.94(1.54-2.44)$ & $<0.0001$ \\
\hline Chronic lung disease ${ }^{\ddagger}(\%)$ & $11(2.6)$ & $25(12.0)$ & $2.27(1.27-2.91)$ & $<0.0001$ \\
\hline Chronic cardiovascular disease ${ }^{\S}(\%)$ & $15(3.5)$ & 59 (28.6) & $3.00(2.51-3.59)$ & $<0.0001$ \\
\hline Chronic renal failure (\%) & $17(4.0)$ & $21(10.1)$ & $1.76(1.29-2.40)$ & 0.0041 \\
\hline Chronic debilitating diseases" (\%) & $8(1.9)$ & $17(8.2)$ & $2.17(1.62-2.91)$ & 0.0003 \\
\hline Immunosuppression" (\%) & $60(14.0)$ & $42(20.2)$ & $1.36(1.04-1.77)$ & 0.0428 \\
\hline Charlson Index $\geq 1$ & $134(31.4)$ & $136(65.4)$ & $2.55(2.00-3.24)$ & $<0.0001$ \\
\hline $0(\%)$ & $283(68.6)$ & $72(34.6)$ & $0.42(0.33-0.53)$ & $<0.0001$ \\
\hline $1-2(\%)$ & $87(20.4)$ & $80(38.5)$ & $1.75(1.41-2.17)$ & $<0.0001$ \\
\hline $3-4(\%)$ & $22(5.1)$ & $42(20.2)$ & $2.26(1.81-2.81)$ & $<0.0001$ \\
\hline$\geq 5(\%)$ & $25(5.8)$ & $14(5.7)$ & $1.10(0.71-1.70)$ & 0.7984 \\
\hline Nosocomial acquisition (\%) & $14(3.3)$ & $11(5.3)$ & $1.36(0.86-2.15)$ & 0.3149 \\
\hline Recurrent meningitis (\%) & $18(4.2)$ & $10(4.8)$ & $1.09(0.66-1.82)$ & 0.8924 \\
\hline
\end{tabular}

Values expressed as median and interquartile range unless otherwise specified.*Patients may have more than a co-morbid condition. ${ }^{\dagger}$ includes: Solid (53): brain (9), lung (6), breast (6), cavum (6), prostate (4), colon (3), endometrium (2), pharynx (2), ovarian (2), urinary bladder (2), pleural mesothelioma (2), skin (2), testes (1), endometrial (1), cervix (1), sphenoidal sinus (1), oesophagus (1), gastric (1), and vagina (1), and haematological (33) cancers: multiple myeloma (8), Hodgkin's lymphoma (3), non-Hodgkin's lymphoma (6), acute leukemias (8), chronic leukemias (7), and Waldenström disease (1). ${ }^{\ddagger}$ Includes: chronic bronchitis (28), asthma (4), idiopathic pulmonary fibrosis (2), other pneumopathies (2) ${ }^{\S}$ Includes: arterial hypertension (40), coronary heart disease (18), congestive heart failure (15), valvular disease (8), chronic arrythmias (3), and Buerguer 's disease (1). "Include: prior stroke (9), senile dementia (7), hyperthyroidism (3), hypothyroidism (2), cerebral palsy (2), chronic hydrocephalus (2), amyloidosis (1). "Includes: antineoplastic chemotherapy (49), hypogammaglobulinemia (22), chronic corticosteroid therapy (21), AIDS (6), splenectomy (6), hypocomplementemia (5), neutropenia (4), and radiotherapy (4). 
Table 2 Clinical features of patients with acute bacterial meningitis according to age group*

\begin{tabular}{|c|c|c|c|c|}
\hline & Group I (non-elderly) & Group II (elderly) & RR $(95 \% \mathrm{Cl})$ & $P$ value \\
\hline & $N=427$ & $N=208$ & & \\
\hline Interval symptoms-admission (hrs) & $24.0(24.0-37.0)$ & $27.5(24.0-37.0)$ & -— & 0.3822 \\
\hline Prior antimicrobial therapy (\%) & $126(29.5)$ & $77(37.0)$ & $1.25(1.00-1.57)$ & 0.0696 \\
\hline Extrameningeal infection ${ }^{\dagger}(\%)$ & $96(22.5)$ & 79 (37.9) & $1.61(1.29-2.00)$ & $<0.0001$ \\
\hline Pneumonia (\%) & $17(4.0)$ & $20(9.6)$ & $1.72(1.25-2.37)$ & 0.0077 \\
\hline ENT infection (\%) & $56(8.8)$ & $33(5.2)$ & $1.16(0.86-1.56)$ & 0.4149 \\
\hline Urinary tract infection (\%) & $9(1.4)$ & $18(2.8)$ & $2.13(1.59-2.86)$ & 0.0003 \\
\hline Fever (\%) & $412(96.5)$ & $193(92.8)$ & $0.64(0.44-0.93)$ & 0.0625 \\
\hline \multicolumn{5}{|l|}{ Level of consciousness (\%) } \\
\hline Normal (\%) & $174(40.7)$ & 49 (23.6) & $0.57(0.43-0.75)$ & $<0.0001$ \\
\hline Abnormal (\%) & $229(62.6)$ & $142(68.3)$ & $1.53(1.20-1.93)$ & 0.0006 \\
\hline Coma (\%) & $24(5.6)$ & $17(8.2)$ & $1.39(0.95-2.04)$ & 0.1639 \\
\hline Neck stiffness (\%) & $357(83.6)$ & $129(62.0)$ & $0.50(0.41-0.62)$ & $<0.0001$ \\
\hline Meningeal triad present (\%) & $208(48.7)$ & $104(50.0)$ & $1.04(0.83-1.29)$ & 0.8275 \\
\hline Skin rash (\%) & $153(35.8)$ & $19(9.1)$ & $0.27(0.17-0.62)$ & $<0.0001$ \\
\hline Interval admission-therapy (hrs) & $3.0(1.0-6.0)$ & $4.0(2.0-12.0)$ & - - & $<0.0001$ \\
\hline Focal neurologic signs on admission (\%) & $63(14.7)$ & $43(20.7)$ & $1.30(1.00-1.69)$ & 0.0777 \\
\hline Seizures on admission (\%) & $33(7.7)$ & $13(6.2)$ & $0.85(0.53-1.37)$ & 0.6091 \\
\hline Cerebral computed tomography (\%) & $163(57.8)$ & $113(75.8)$ & $1.55(1.24-1.93)$ & 0.0002 \\
\hline
\end{tabular}

Values expressed as median and interquartile range unless otherwise specified. ENT = ear, nose and throat. ${ }^{*}$ A patient may have more than an extrameningeal focus of infection. ${ }^{\dagger}$ Includes: otiitis (73), pneumonia (37), urinary tract infection (27), paranasal sinusitis (23), endocarditis (7), pyelonephritis (4), acute bronchitis (4), tonsillitis (3), parappharyngeal abscess (2), cholecystitis (2), peritonitis (2), ventriculo-peritoneal shunt (2), dental abscess (2), scrotal abscess (1), psoas abscess (1), i.v. catheter (1), pacemaker electrode infection (1).

higher probability, although not statistically different, of having received out-of-hospital antibiotic therapy. An extra-meningeal focus of infection was found more frequently in patients from group II, and this was especially true for pneumonia and infra-diaphragmatic foci of infection $(\mathrm{RR}=1.66 ; 95 \% \mathrm{CI}: 1.20-2.29, \mathrm{P}=0.0126)$. Elderly patients more frequently lacked fever (although the difference did not reach statistical significance), neck stiffness and skin rash, but had an altered level of consciousness more often (Table 2). Despite being brought to the hospital with an interval similar to that of younger patients, elderly patients suffered a greater delay from arrival to the hospital to starting antibiotic therapy. Cerebral computed tomography $(\mathrm{CT})$ on admission was performed in 163 (57.8\%), and 113 (75.8\%) patients from groups I and II, respectively (Table 2).

\section{CSF findings, microbiologic features and etiology}

CSF cyto-biochemical and microbiological findings are summarized in Table 3. CSF protein content was significantly higher in patients from group II whereas they had a lower diagnostic yield for the CSF Gram-stained smear. The median CSF/blood glucose ratio was not statistically different for immunosuppressed and immunocompetent patients after excluding diabetic patients (0.240 \{nterquartile range: $0.091-0.405\}$ vs. 0.220 \{IQR: $0.0070-0.440\}, \mathrm{P}=0.5402$ ). The median CSF cell count in immunosuppressed patients was 560 cells/ $\mathrm{mm}^{3}$ (IQR: 173-1891) whereas in immunocompetent patients it was 1178 (IQR: $327-3036)$ cells $/ \mathrm{mm}^{3}(\mathrm{P}=$ 0.0029 ). Blood cultures were most frequently positive in elderly patients, although the difference did not reach statistical significance. Meningococcal meningitis was diagnosed less frequently whereas pneumococcal meningitis was diagnosed more often in the elderly, although the former difference was not statistically significant. Listerial meningitis, gram-negative bacillary meningitis, and meningitis of unknown origin also showed increases in group II (Table 3). Meningococcal isolates from elderly patients showed decreased susceptibility to penicillin more frequently $(27.3 \%$ vs. $5.5 \%, R R=1.57 ; 95 \%$ CI: $0.99-2.47$, $\mathrm{P}=0.0025)$, whereas penicillin-resistant pneumococcal isolates were evenly distributed between both groups (14.3\% vs. $11.9 \%, \mathrm{RR}=1.09$; $95 \%$ CI: $0.41-1.69, \mathrm{P}=0.8771$ ). The percentage of serogroup $\mathrm{C}$ meningococcal isolates fell from $45.8 \%$ to $11.1 \%$ before and after the vaccination campaign of the year $2000(\mathrm{RR}=0.25$; 95\% CI: $0.08-0.75 \mathrm{P}=$ 0.0050). Similarly, pneumococcal serotypes included in the heptavalent vaccine fell from $38.4 \%$ to $22 \%$ after 2001 $(\mathrm{OR}=2.21$; 95\% CI: 0.99-5.09, $\mathrm{P}=0.0539)$. 
Table 3 CSF findings, microbiologic features and etiology of acute bacterial meningitis according to age group

\begin{tabular}{|c|c|c|c|c|}
\hline & Group I (non-elderly) & Group II (elderly) & RR $(95 \% \mathrm{Cl})$ & $P$ value \\
\hline & $N=427$ & $N=208$ & & \\
\hline \multicolumn{5}{|l|}{ CSF findings } \\
\hline Protein content, g/l & $3.2(1.5-6.5)$ & $3.8(1.8-7.3)$ & - - & 0.0306 \\
\hline $\mathrm{mg} / \mathrm{dl}$ & $320(150-650)$ & $380(180-730)$ & & \\
\hline CSF/plasma glucose ratio & $0.24(0.07-0.45)$ & $0.22(0.08-0.42)$ & - - & 0.7681 \\
\hline Cells $/ \mathrm{mm}^{3}$ & $1022(301-2993)$ & $1026(290-2968)$ & - & 0.7490 \\
\hline Predominance $\mathrm{PML}^{\dagger}$ & $385(94.4)$ & $183(91.5)$ & $0.76(0.52-1.11)$ & 0.2446 \\
\hline Positive CSF Gram stained smear (\%) & $199(46.6)$ & $68(32.7)$ & $0.67(0.52-0.85)$ & 0.0012 \\
\hline Positive CSF culture (\%) & $309(72.4)$ & $141(67.8)$ & $0.87(0.68-1.09)$ & 0.2721 \\
\hline Positive blood culture $(\%)^{\ddagger}$ & $184(43.4)$ & $104(51.5)$ & $1.25(1.00-1.58)$ & 0.0616 \\
\hline \multicolumn{5}{|l|}{ Etiology ${ }^{\S}$} \\
\hline Meningococcal (\%) & $179(41.9)$ & $24(11.5)$ & $0.28(0.19-0.41)$ & $<0.0001$ \\
\hline Pneumococcal (\%) & $91(21.3)$ & $59(28.4)$ & $1.28(1.01-1.63)$ & 0.0622 \\
\hline Listerial \& grampositive bacilli (\%) & $33(7.7)$ & $29(13.9)$ & $1.93(1.12-2.01)$ & 0.0196 \\
\hline Other Gram-positive cocci (\%) & $22(5.1)$ & $13(6.2)$ & $1.14(0.73-1.79)$ & 0.7012 \\
\hline Gram-negative bacilli (\%) & $18(4.2)$ & $21(10.1)$ & $1.72(1.25-2.35)$ & 0.0065 \\
\hline Haemophilus influenzae (\%) & $9(2.1)$ & $5(2.4)$ & $1.09(0.54-2.23)$ & 0.9685 \\
\hline Mixed (\%) & $2(0.5)$ & $2(1)$ & $1.53(0.57-4.11)$ & 0.8393 \\
\hline Other & $2(0.5)$ & $1(0.5)$ & $1.02(0.20-5.06)$ & 0.5517 \\
\hline Unknown origin (\%) & $71(16.5)$ & $54(25.9)$ & $1.43(1.12-1.82)$ & 0.0076 \\
\hline
\end{tabular}

Values expressed as median and interquartile range unless otherwise specified. CSF = cerebrospinal fluid. PML polymorphonuclear leukocytes. ${ }^{\dagger}$ Differential count performed in 608 patiens. ${ }^{\sharp}$ Blood culture performed in 624 patients. ${ }^{\S}$ Gram-positive bacilli: Listeria monocytogenes (60) and Bacillus cereus (2). Gram-positive cocci: Staphylococcus aureus (12), Streptococcus agalactiae (8), Streptococcus viridans (4), Streptococcus pyogenes (3), Enterococcus faecalis (2), Staphylococcus epidermidis (2), Streptococcus anginosus (1), Staphylococcus sp. (1), Group G streptococcus (1), Streptococcus bovis (1). Gram-negative bacilli: Escherichia coli (17), Pseudomonas aeruginosa (8), Pseudomonas sp. (3), Serratia sp. (2), Klebsiella sp. (2), Proteus mirabilis (2), Serratia marcescens (1), Acinetobacter baumanii (1), Bacteroides melaninogenicus (1), and Citrobacter freundii (1), and Enterobacter cloacae (1). Mixed meningitis: Bacteroides intermedius + Streptococcus viridans (1), Enterobacter cloacae + Streptococcus viridans (1), Peptostreptococcus sp. + anaerobic unidentified GNB (1), and Peptostreptococcus sp. + Bacteroides sp. (1). Other: Brucella sp. (2) and Neisseria subflava (1).

\section{Evolving features and outcome}

Elderly patients developed more frequently coma, and cranial nerve palsies of new appearance. Patients from group II also developed acute respiratory failure and acute renal failure more frequently (Table 4). Almost $90 \%$ of patients in each group received adequate empiric antibiotic therapy.

The overall mortality ratio was significantly higher for patients in group II (29.8\% vs. $11.7 \%)$ (Table 4$)$. This higher mortality rate was caused by a higher mortality rate of pneumococcal and of meningitis of unknown origin. Survival curves for both groups of patients showed an earlier probability of death for elderly patients (Figure 1). When death directly attributable to ABM was considered, the probability of dying was again higher for elderly patients. Development of complications conveyed higher rates of mortality in both groups, without statistically significant differences between them (Table 5). There were no differences between groups with respect to postmeningitic sequelae.

\section{Discussion}

Our study shows that elderly patients are at much higher risk of developing $\mathrm{ABM}$ than younger adults. We also observed a change in the etiology of the disease, Neisseria meningitidis ranked first for younger patients, whereas it was surpassed by pneumococcal, listerial, and meningitis of unknown origin in the elderly. Another important, although expectable, change is the increased prevalence of co-morbid conditions among elderly people. This may have an impact, not only on the etiology of ABM, but also on the rate of complications and eventually on mortality. Other differing findings for elderly people include a higher chance of having received out-of-hospital antibiotic therapy, more frequently lacking fever, neck stiffness and skin rash, developing neurologic and extra-neurologic complications more frequently, and having an increased risk of death because of ABM. In summary, the linkage and interaction of higher co-morbidity, different etiologic spectrum, more pre-admission antibiotic therapy and subtler clinical manifestations may contribute to explain most of the differences between elderly and younger patients. 
Table 4 Evolving features and outcome of acute bacterial meningitis according to age group*

\begin{tabular}{|c|c|c|c|c|}
\hline & Group I (non-elderly) & Group II (elderly) & RR (95\% Cl) & $P$ value \\
\hline & $N=427$ & $N=208$ & & \\
\hline Neurologic complications (\%) & $80(18.7)$ & $64(30.8)$ & $1.52(1.21-1.90)$ & 0.0009 \\
\hline New focal neurologic signs (\%) & $23(5.4)$ & $16(7.7)$ & $1.27(0.86-1.89)$ & 0.3372 \\
\hline Coma (\%) & $57(13.3)$ & $48(23.1)$ & $1.51(1.18-1.94)$ & 0.0028 \\
\hline Seizures (\%) & $46(10.7)$ & $33(15.9)$ & $1.33(1.00-1.77)$ & 0.0897 \\
\hline New cranial palsies (\%) & $17(4.0)$ & $17(8.2)$ & $1.57(1.10-2.25)$ & 0.0439 \\
\hline Extra-neurologic complications (\%) & $109(25.5)$ & $94(45.2)$ & $1.75(1.41-2.18)$ & $<0.0001$ \\
\hline Septic shock (\%) & $65(15.2)$ & $35(16.8)$ & $1.08(0.80-1.44)$ & 0.7125 \\
\hline Acute respiratory failure (\%) & $60(14.0)$ & $46(22.1)$ & $1.42(1.10-1.82)$ & 0.0145 \\
\hline Acute renal failure (\%) & $40(9.4)$ & $48(23.1)$ & $1.86(1.48-2.35)$ & $<0.0001$ \\
\hline Consumption coagulopathy (\%) & $39(9.1)$ & $15(7.2)$ & $0.84(0.54-1.31)$ & 0.5071 \\
\hline \multicolumn{5}{|l|}{ Therapeutics } \\
\hline Adequate empiric antibiotic therapy (\%) & $398(93.2)$ & $187(89.9)$ & $0.76(0.54-1.08)$ & 0.1956 \\
\hline Dexamethasone therapy (\%) & $142(33.2)$ & $83(39.9)$ & $1.21(0.97-1.52)$ & 0.1198 \\
\hline Vasoactive drugs (\%) & $69(16.1)$ & $38(18.3)$ & $1.10(0.83-1.46)$ & 0.5797 \\
\hline Mechanical ventilation (\%) & $67(15.7)$ & $39(18.7)$ & $1.15(0.87-1.52)$ & 0.3915 \\
\hline Dialysis (\%) & $9(2.1)$ & $8(3.8)$ & $1.45(0.87-2.44)$ & 0.3116 \\
\hline \multicolumn{5}{|l|}{ Outcome } \\
\hline Overall mortality rate (\%) & $50(11.7)$ & $62(29.8)$ & $1.98(1.60-2.46)$ & $<0.0001$ \\
\hline Meningococcal (\%) & $8(4.5)$ & $3(12.5)$ & $2.49(0.88-7.10)$ & 0.2494 \\
\hline Pneumococcal (\%) & $14(15.0)$ & $19(31.7)$ & $1.68(1.14-2.48)$ & 0.0259 \\
\hline Listerial \& grampositive bacilli (\%) & $7(21.2)$ & $9(31.0)$ & $1.29(0.75-2.23)$ & 0.5544 \\
\hline Other grampositive cocci (\%) & $9(40.9)$ & $6(46.1)$ & $1.14(0.48-2.70)$ & 0.9597 \\
\hline Gramnegative bacilli (\%) & $10(55.5)$ & $12(57.1)$ & $1.03(0.57-1.86)$ & 0.8225 \\
\hline Haemophilus influenzae (\%) & $1(11.1)$ & $0(0.0)$ & $1.50(0.30-7.43)$ & 0.7320 \\
\hline Mixed (\%) & $0(0.0)$ & $0(0.0)$ & - & - \\
\hline Other & $0(0)$ & $0(0.0)$ & - & - \\
\hline Unknown etiology (\%) & $1(1.4)$ & $13(24.1)$ & $2.51(1.89-3.34)$ & 0.0002 \\
\hline Death attributable to meningitis (\%) & $42(9.8)$ & $43(20.7)$ & $1.67(1.30-2.13)$ & 0.0004 \\
\hline Post-meningitic sequelae $^{\dagger}(\%)$ & $42(11.1)$ & $21(14.4)$ & $1.22(0.83-1.78)$ & 0.3945 \\
\hline
\end{tabular}

Values expressed as median and interquartile range unless otherwise specified. ${ }^{*}$ A patient may have more than one complication or sequelae. ${ }^{\dagger}$ Sequelae: total or partial deafness (19), limb palsy (18), cranial nerve palsy (13), memory disturbances (10), vegetative state (5), speech disturbances (4), polyneuritis (3), blindness (3), bilateral leg amputation (2), seizures (2), myoclonia (2), hydrocephalus (1), chronic leg ulcers (1), long-term tracheostomy (1), and chronic renal failure (1).

However, our work has inherent limitations. First, our study is based on a single hospital and this may imply that the results may only be applicable to places with a population structure and local ecology similar to ours. However, changes in the spectrum of ABM similar to those observed in our study have been described, especially those referring to the epidemiology of meningococcal disease [2,24-26]. Moreover, the pattern of population change documented in Spain, has also been reported in other Western, mainly European countries [27]. Therefore, the population scenario may resemble that described in the present work. Our study spans over a long period of time; during 30 years it is obvious that the treatment and management of critically ill patients and of ABM have changed a lot. Although the case record forms were standardized and remained the same throughout the study, they may reflect differing sensitivities among treating physicians and in the end are a reflection of the "real world". An important part of this real world is meningitis of unknown origin which is the most diagnosis-challenging ABM. We had strict criteria for this diagnosis, and when reasonable doubts arose, the case was not included in our series.

Changes in population structure contribute to changes in the spectrum of ABM. During the study period, Barcelona population has ranged from 1,754,900 


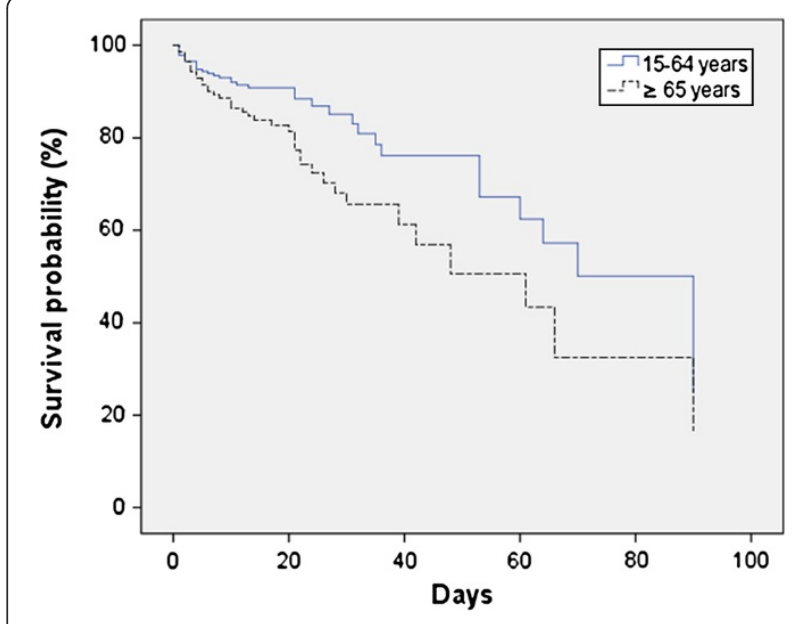

Figure 1 Survival curves for adult patients with acute bacterial meningitis according to age $(P=0.007)$.

inhabitants in 1982 to $1,619,337$ in 2010 , with a minimum of 1,508,805 in 1996 [28]. However, the elderly population increased from 252,415 inhabitants in 1986 to 419,988 in 2006 , whereas the population aged 15-24 years decreased from 266,791 in 1986 to 157,737 in 2006 [28]. Therefore, a decrease in the population more prone to meningococcal meningitis was observed together with an increase in the population more susceptible to having pneumococcal and listerial meningitis. Surprisingly, meningitis of unknown origin also significantly increased in group II, which may be explained by a higher prevalence of out-of-hospital antibiotic therapy among elderly people. The negative impact of pre-admission antibiotic therapy on the positivity of microbiological tests is well known [12,29].

Although N. meninigitidis is not a common cause of ABM in elderly patients, our epidemiological environment has for many years been one of high endemicity of meningococcal disease [24,30,31]. Moreover, the incidence of disease due to serogroup $\mathrm{C}$ meningococci increased in Spain from the mid-nineties [32]. This change of pattern led to the carrying out of a mass vaccination campaign against serogroup $C$ in Spain and to inclusion of the meningococcal $C$ conjugate vaccine in the routine vaccination schedule [33]. Since group C meningococci have a predilection for causing disease in older adults [12], the vaccination campaign may also have contributed to the decreased incidence of meningococcal meningitis among the elderly as our results show. This can be explained by the increase in herd immunity [34].

With respect to clinical findings, although elderly patients were brought to the hospital not later than younger ones, the time before first antibiotic dose was significantly longer. There are a cluster of circumstances that may explain this finding; elderly patients had taken out-ofhospital antibiotic therapy more frequently, and this, together with being older, makes the symptoms and signs of $\mathrm{ABM}$ subtler, as exemplified by the less frequent presence of symptoms and/or signs of $\mathrm{ABM}$ and skin lesions [15,29,35-38], which may eventually lead to a diagnostic delay. But, above all, elderly patients had a cerebral CT performed more frequently, and this delayed the spinal tap and consequently the start of antibiotic therapy. Delay

Table 5 Outcome of acute bacterial meningitis according to age group and severity indexes*

\begin{tabular}{|c|c|c|c|c|}
\hline & Group I (non-elderly) & Group II (elderly) & RR $(95 \% \mathrm{Cl})$ & $P$ \\
\hline & $N=427$ & $N=208$ & & \\
\hline \multicolumn{5}{|l|}{ Type of complication (\%) } \\
\hline None (\%) & $3 / 292(1.03)$ & 3/93 (3.2) & $3.07(0.63-14.97)$ & 0.3263 \\
\hline Neurologic complications (\%) & $9 / 26(34.6)$ & $11 / 21(52.4)$ & $1.34(0.64-2.80)$ & 0.6124 \\
\hline Extra-neurologic complications (\%) & $8 / 55(14.5)$ & $11 / 51(29.4)$ & $1.79(0.82-3.93)$ & 0.2085 \\
\hline Both types (\%) & $30 / 54(55.5)$ & $33 / 43(76.7)$ & $1.22(0.83-1.79)$ & 0.4041 \\
\hline \multicolumn{5}{|l|}{ Extra-neurologic complications (\%) } \\
\hline New focal neurologic signs (\%) & $13 / 23(56.5)$ & $11 / 16(68.7)$ & $1.13(0.60-2.12)$ & 0.9105 \\
\hline Coma (\%) & $37 / 57(64.9)$ & $41 / 48(85.4)$ & $1.17(0.84-1.64)$ & 0.4429 \\
\hline Seizures (\%) & $16 / 46(34.8)$ & 21/33 (63.6) & $1.51(0.88-2.58)$ & 0.1908 \\
\hline New cranial palsies (\%) & $4 / 17(23.5)$ & $11 / 17(64.7)$ & $2.06(0.76-5.58)$ & 0.2270 \\
\hline \multicolumn{5}{|l|}{ Extra-neurologic complications (\%) } \\
\hline Septic shock (\%) & $30 / 65(46.1)$ & 23/35 (74.3) & $1.35(0.89-2.04)$ & 0.2178 \\
\hline Acute respiratory failure (\%) & $22 / 60(36.7)$ & $27 / 46(58.7)$ & $1.38(0.86-2.20)$ & 0.2360 \\
\hline Acute renal failure (\%) & $19 / 40(47.5)$ & $27 / 48(56.2)$ & $1.12(0.69-1.80)$ & 0.7823 \\
\hline Consumption coagulopathy (\%) & $19 / 39(48.7)$ & $11 / 15(73.3)$ & $1.29(0.72-2.31)$ & 0.5497 \\
\hline
\end{tabular}

Values expressed as patients who died/total number of patients with complication. ${ }^{*}$ A patient may have more than one complication or sequelae. 
in starting antibiotic therapy has been advocated as a main factor in ABM-driven mortality [36-42]. Therefore, a high index of suspicion of $\mathrm{ABM}$ is needed in elderly patients with fever and CNS dysfunction to rule out meningeal infection eventually leading to a prompt spinal tap and early starting of empiric antibiotic therapy.

There were no differences between both groups in terms of CSF parameters except for a higher CSF protein content for group II patients, which is most likely due to the predominance of pneumococcal, listerial and gramnegative bacillary meningitis in this group. We know that these meningitis have a higher CSF protein content than meningococcal which predominates among group I patients (data not shown). Underlying immune suppression may cause changes in CSF parameters; and we found like Erdem et al. [37] lower CSF counts in immunosuppressed patients but not a different CSF/blood glucose ratio. In addition, the diagnostic yield of CSF Gram-stained smear was inferior in elderly patients, but we must take into account that pre-admission antibiotic therapy had been taken by $37 \%$ of patients, and we know that this is the most frequent cause of meningitis with negative CSF Gram-stained smears [35,43,44].

Both neurologic and extra-neurologic complications appeared more frequently in elderly patients. This may be explained by two facts; first, the physiological reserve and the ability of many organs and systems to respond to insults decrease with age, and second, in elderly patients, the baseline organ function may be compromised because of prior co-morbid conditions. Therefore, ABM and/or its associated systemic consequences may further damage an already dysfunctional organ, eventually leading to its failure. However, once present, they usually convey high mortality rates both in young and elder patients. The excess mortality of $\mathrm{ABM}$ in elderly people is a usual finding in related literature $[37,38,44,45]$. In fact, this difference in mortality rate is mainly driven by an excess mortality in pneumococcal and meningitis of unknown origin.

\section{Conclusions}

In summary, elderly people are at higher risk of having $\mathrm{ABM}$ than younger adults, $\mathrm{ABM}$ appears more frequently in patients with co-morbid conditions, is associated with a longer interval from admission to antibiotic therapy, is caused by S. pneumoniae, and patients develop neurologic and extra-neurologic complications more frequently. $\mathrm{ABM}$ in elderly patients is associated with an earlier and higher mortality rate than in younger ones.

\section{Competing interests}

There are no competing interests to be disclosed.

\section{Authors' contributions}

PD and VP designed the database, analyzed the results and wrote the paper. NB analyzed the results and performed statistical studies. PC performed the microbiological studies and wrote the microbiological parts of the study. All authors have read and approved the final manuscript.

\section{Acknowledgements}

Pere Domingo is supported by a grant from the Programa de Intensificación de Investigadores, Instituto de Salud Carlos III (INT12/383).

\section{Author details}

${ }^{1}$ Infectious Diseases Unit, Hospital de la Santa Creu i Sant Pau, Universitat Autònoma de Barcelona, Av. Sant Antoni Ma Claret, 167, Barcelona 08025, Spain. ${ }^{2}$ Department of Microbiology, Hospital de la Santa Creu i Sant Pau, Universitat Autònoma de Barcelona, Barcelona, Spain.

Received: 3 September 2012 Accepted: 19 February 2013

Published: 27 February 2013

\section{References}

1. Morris SK, Moss WJ, Halsey N: Haemophilus influenzae type b conjugate vaccine use and effectiveness. Lancet Infect Dis 2008, 8:435-443.

2. Thigpen MC, Whitney CG, Messonnier NE, Zell ER, Lynfield R, Hadler JL, Harrison LH, Farley MM, Reingold A, Bennett NM, Craig AS, Schaffner W, Thomas A, Lewis MM, Scallan E, Schuchat A: Bacterial meningitis in the United States, 1998-2007. N Engl J Med 2011, 364:2016-2025.

3. Verani JR, Schrag SJ: Group B streptococcal disease in infants: progress in prevention and continued challenges. Clin Perinatol 2010, 37:375-392.

4. Brouwer MC, Tunkel AR, van de Beek D: Epidemiology, diagnosis, and antimicrobial treatment of acute bacterial meningitis. Clin Microbiol 2010, 23:467-492

5. Meningococcal Disease Surveillance Group: Meningococcal disease: secondary attack rate and chemoprophylaxis in the United States, 1974. JAMA 1976, 235:261-265.

6. Tang L, Chen S, Hsu W, Lyu RK: Acute bacterial meningitis in adults: a hospital-based epidemiological study. QJM 1999, 92:719-725.

7. Durand ML, Calderwood S, Weber D, Miller SI, Southwick FS, Caviness VS Jr, Swartz MN: Acute Bacterial meningitis in Adults. A review of 493 episodes. N Engl J Med 1993, 328:21-28.

8. Murray PR, Baron EJ, Jorgensen JH, Landry ML, Pfaller MA: Manual of Clinical Microbiology. 9th edition. Washington DC: ASM Press; 2007.

9. National Committee for Clinical Laboratory Standards: Performance standards for antimicrobial disc susceptibility test. M2-A4 Vilanova, PA: NCCLS; 1990

10. National Committee for Clinical Laboratory Standards: Methods for dilution antimicrobial susceptibility test for bacteria that grow aerobically. M7-A2 Vilanova, PA: NCCLS; 1990.

11. Clinical and Laboratory Standards Institute (CLSI): Performance standards for antimicrobial susceptibility testing: Eighteenth Informational Supplement. M100-S18. Wayne, PA: CLSI; 2008.

12. Barquet N, Domingo $P$, Caylà JA, González J, Rodrigo C, Fernández-Viladrich $P$, Moraga-Llop FA, Marco F, Vázquez J, Sáez-Nieto JA, Casal J, Canela J, Foz M: Meningococcal disease in a large urban population (Barcelona, 1987-1992). Predictors of dismal prognosis. Arch Intern Med 1999, 159:2329-2340.

13. World Health Organization: International Guide for monitoring alcohol consumption and related harm. Geneva: World Health Organization; 2000

14. Charlson ME, Pompei P, Ales KL, MacKenzie CR: A new method of classifying prognostic comorbidity in longitudinal studies: development and validation. J Chronic Dis 1987, 140:373-383.

15. Domingo P, Barquet N, Alvarez M, Coll P, Nava J, Garau J: Group B streptococcal meningitis in adults: report of twelve cases and review. Clin Infect Dis 1997, 25:1180-1187.

16. Lu CH, Chang WN, Chuang YC, Chang HW: The prognostic factors of adult Gram-negative bacillary meningitis. J Hosp Infect 1998, 40:27-34.

17. Teasdale $G$, Jennet $B$ : Assessment of coma and impaired consciousness. Lancet 1974, 2:81-84.

18. Pfister H, Leiden W, Einhaupl K: Spectrum of complications during bacterial meningitis in adults. Results of a prospective clinical study. Arch Neurol 1993, 50:575-581.

19. Brandtzaeg P, Kierulf P, Gaustad P, Skulberg A, Bruun JN, Halvorsen S, Sørensen E: Plasma endotoxin as a predictor of multiple organ failure and death in systemic meningococcal disease. J Infect Dis 1989, 159:195-204.

20. Bernard GR, Artigas A, Brigham KL, Carlet J, Falke K, Hudson L, Lamy M, Legall JR, Morris A, Spragg R: The American-European Consensus Conference on 
ARDS. Definitions, mechanisms, relevant outcomes, and clinical trial coordination. Am J Respir Crit Care Med 1994, 149(3 Pt 1):818-824.

21. Knaus WA, Wagner DP, Draper EA: The APACHE III prognostic system. Risk prediction of hospital mortality for critically ill hospitalised adults. Chest 1997, 1100:1619-1636.

22. Barquet N, Domingo P, Caylà JA, González J, Rodrigo C, Fernández-Viladrich P, Moraga-Llop FA, Marco F, Vázquez J, Sáez-Nieto JA, Casal J, Canela J, Foz M: Prognostic factors in meningococcal disease. Development of a bedside predictive model and scoring system. Barcelona Meningococcal Disease Surveillance Group. JAMA 1997, 278:491-496.

23. McMillan DA, Lin CY, Aronin SI, Quagliarello VJ: Community-acquired bacterial meningitis in adults: categorization of causes and timing of death. Clin Infect Dis 2001, 33:969-975.

24. Martínez Al, Dominguez A, Oviedo M, Minguell S, Jansa JM, Codina G, Vazquez JA: Changes in the evolution of meningococcal disease, 20012008, Catalonia (Spain). Vaccine 2009, 27:3496-3498

25. Cohn AC, MacNeil JR, Harrison LH, Hatcher C, Theodore J, Schmidt M, Pondo T, Arnold KE, Baumbach J, Bennett N, Craig AS, Farley M, Gershman K, Petit S, Lynfield R, Reingold A, Schaffner W, Shutt KA, Zell ER, Mayer LW, Clark T, Stephens D, Messonnier NE: Changes in Neisseria meningitidis disease epidemiology in the United States, 1998-2007: implications for prevention of meningococcal disease. Clin Infect Dis 2010, 50:184-191.

26. Trotter CL, Chandra M, Cano R, Larrauri A, Ramsay ME, Brehony C, Jolley KA, Maiden MC, Heuberger S, Frosch M: A surveillance network for meningococcal disease in Europe. FEMS Microbiol Rev 2007, 31:27-36.

27. European Commission. Eurostat (2011) Population structure and ageing. [http://epp.eurostat.ec.europa.eu/statistics_explained/index.php/ Population_structure_and_ageing]. Accessed November 17, 2011.

28. Institut d'Estadistica de Catalunya. [http://www.idescat.cat/.] Accessed November 10, 2011.

29. Ferguson R: The effect of antibiotic therapy before admission to hospital on recognition of the causative organism in acute bacterial meningitis. $J$ Infect 1986, 13:241-244.

30. Peltola H: Meningococcal disease: still with us. Rev Infect Dis 1983, 5:71-91.

31. Schwartz B, Moore PS, Broome CV: Global epidemiology of meningococcal disease. Clin Microbiol Rev 1989, 2:118S-124S.

32. Cartwright $\mathrm{K}$, Noah N, Peltola $\mathrm{H}$, the Meningococcal Advisory Board: Meningococcal disease in Europe: epidemiology, mortality, and prevention with conjugate vaccines. Vaccine 2001, 19:4347-4356

33. Salleras $L$, Dominguez A, Cardeñosa N: Impact of mass vaccination with polysaccharide conjugate vaccine against serogroup $\mathrm{C}$ meningococcal disease in Spain. Vaccine 2003, 21:725-728.

34. Trotter $\mathrm{CL}$, Maiden MC: Meningococcal vaccines and herd immunity: lessons learned from serogroup $C$ conjugate vaccination programs. Expert Rev Vaccines 2009, 8:851-861

35. Bohr V, Rasmussen N, Hansen B, Kjersem H, Jessen O, Johnsen N, Kristensen HS: 875 cases of bacterial meningitis: diagnostic procedures and the impact of preadmission antibiotic therapy. Part III of a three-part series. J Infect 1983, 7:193-202.

36. Proulx N, Fréchette D, Toye B, Chan J, Kravcik S: Delays in the administration of antibiotics are associated with mortality from adult acute bacterial meningitis. QJM 2005, 98:291-298.

37. Erdem H, Kilic S, Coskun O, Ersoy Y, Cagatay A, Onguru P, Alp S, Members of the Turkish Bacterial Meningitis in the Elderly Study Group: Communityacquired acute bacterial meningitis in the elderly in Turkey. Clin Microbiol Infect 2010, 16:1223-1229.

38. Lai WA, Chen SF, Tsai NW, Chang CC, Chang WN, Lu CH, Chuang YC, Chien CC, Huang CR: Clinical characteristics and prognosis of acute bacterial meningitis in elderly patients over 65 : a hospital-based study. BMC Geriatr 2011, 11:91

39. Aronin SI, Peduzzi P, Quagliarello VJ: Community-acquired bacterial meningitis: risk stratification for adverse clinical outcome and effect of antibiotic timing. Ann Intern Med 1998, 1998(129):862-869.

40. Hasbun R, Abrahams J, Jekel J, Quagliarello VJ: Computed tomography of the head before lumbar puncture in adults with suspected meningitis. $N$ Engl J Med 1993, 345:1727-1733.

41. Auburtin M, Wolff M, Charpentier J, Varon E, Le Tulzo Y, Girault C, Mohammedi I, Renard B, Mourvillier B, Bruneel F, Ricard JD, Timsit JF: Detrimental role of delayed antibiotic administration and penicillinnonsusceptible strains in adult intensive care unit patients with pneumococcal meningitis: the PNEUMOREA prospective multicenter study. Crit Care Med 2006, 34:2758-2765.

42. Talan D, Zibulewsky J: Relationship of clinical presentation to time to antibiotics for the emergency department management of suspected bacterial meningitis. Ann Emerg Med 1993, 22:1733-1738.

43. Andersen J, Backer $\mathrm{V}$, Jensen $\mathrm{E}$, Voldsgaard $\mathrm{P}$, Wandall $\mathrm{JH}$ : Acute meningitis of unknown aetiology: analysis of 219 cases admitted to hospital between 1977 to 1990. J Infect 1995, 31:113-122.

44. Cabellos C, Verdaguer R, Olmo M, Fernández-Sabé N, Cisnal M, Ariza J, Gudiol F, Viladrich PF: Community-Acquired Bacterial Meningitis in Elderly Patients. Experience Over 30 Years. Medicine 2009, 88:115-119.

45. de Gans J, van de Beek D, the European Dexamethasone in Adulthood Bacterial Meningitis Study Investigators: Dexamethasone in adults with bacterial meningitis. N Engl J Med 2002, 347:1549-1556.

doi:10.1186/1471-2334-13-108

Cite this article as: Domingo et al:: The spectrum of acute bacterial meningitis in elderly patientsThe spectrum of acute bacterial meningitis in elderly patients. BMC Infectious Diseases 2013 13:108.

\section{Submit your next manuscript to BioMed Central and take full advantage of:}

- Convenient online submission

- Thorough peer review

- No space constraints or color figure charges

- Immediate publication on acceptance

- Inclusion in PubMed, CAS, Scopus and Google Scholar

- Research which is freely available for redistribution 